\title{
Radial Distribution Function Analyses of Amorphous Carbon Films Containing Silicon and Hydrogen by Energy-Filtered Diffraction and EXELFS
}

\author{
J. Bentley, ${ }^{*}$ R.D. Evans, ${ }^{\ddagger}{ }^{\S}$ K.L. More, ${ }^{*}$ D.W. Coffey, ${ }^{*}$ G.L. Doll, ${ }^{\ddagger}$ and J.T Glass ${ }^{\circledR}$ \\ *Metals \& Ceramics Division, Oak Ridge National Laboratory, PO Box 2008, Oak Ridge, TN 37831 \\ ${ }^{\ddagger}$ Materials Technology, The Timken Company, Canton, OH 44706 \\ ${ }^{\S}$ Department of Chemical Engineering, Case Western Reserve University, Cleveland, OH 44106 \\ IDepartment of Electrical and Computer Engineering, Duke University, Durham, NC 27708
}

Short-range order in amorphous materials is most commonly characterized with the use of radial distribution functions (RDFs). Two analytical electron microscopy methods were used in this study to measure RDFs from amorphous carbon films containing different levels of silicon and hydrogen $(\mathrm{Si}-\mathrm{aC}: \mathrm{H})$ : energy-filtered convergent-beam electron diffraction (EFCBED) and extended electron energy-loss fine structure (EXELFS) analyses. The films [1] were deposited in an industrial-scale system onto a thin adhesive titanium layer on silicon substrates by reactive sputtering of carbon with a feed gas of tetramethyl silane (TMS) and argon, to produce a series of films with different $\mathrm{Si}$ and $\mathrm{H}$ contents $(\mathrm{Si} / \mathrm{C}=0,0.04,0.10$, and 0.18$)$.

Cross-section TEM specimens were prepared with a Hitachi FB-2000A focused ion beam (FIB) tool (see Fig. 1). To give enough signal without problems of severe multiple scattering, regions with $\mathrm{t} / \lambda \cong$ 0.3 , where $t$ is specimen thickness and $\lambda$ is the inelastic scattering mean-free path, were selected for analysis. For specimens with $\mathrm{Si} / \mathrm{C}=0.04$ and $0.10, \mathrm{EFCBED}$ data were acquired with a Philips CM200FEG equipped with a Gatan imaging filter (GIF), operated at nominally $200 \mathrm{kV}$ with the GIF in image mode and a $10-\mathrm{eV}$ slit centered on the zero-loss peak. The selected-area diffraction (SAD) mode was not used because of the well-known aberration-induced shifts of the selected area at large scattering angles. Rather, regions were selected with a probe spread to $\sim 600 \mathrm{~nm}$ diameter by overfocusing the second condenser lens, resulting in a beam convergence semi-angle $\alpha=1.3 \mathrm{mrad}$. The probe current was $\sim 2 \mathrm{nA}$ to limit beam damage (no such effects were observed). Since at the lowest distortion-free camera length the angular range is limited, post-specimen deflection coils were used to precisely shift diffraction patterns for recording with the GIF CCD camera. Intensity profiles were subsequently spliced together to obtain intensity plots for $\mathrm{s}=0$ to $30 \mathrm{~nm}^{-1}(\mathrm{~s}=2 \sin \theta / \lambda$, where now $\lambda$ is the electron wavelength and $2 \theta$ is the scattering angle). The s scale was calibrated from $<011>\mathrm{Si}$ diffraction patterns from the substrate. The data reduction followed that of Cockayne et al. [2] and details can be found elsewhere [3]. Briefly, reduced scattered intensity functions were extracted and Fourier sine transformed to yield reduced density functions G(r), as shown in Fig. 2. With knowledge of the average atomic density $\rho_{0}$ from measured plasmon energies [4], the RDF J(r) is obtained, Fig. 3. Electron energy-loss spectra (EELS) for carbon-K EXELFS analysis were acquired in diffraction mode at $300 \mathrm{kV}$ with a Philips CM30 equipped with a $\mathrm{LaB}_{6}$ cathode and GIF. A 1-nA probe $\sim 400 \mathrm{~nm}$ in diameter was used with convergence semi-angle $\alpha=1.6 \mathrm{mrad}$, and a collection semi-angle $\beta=8.2 \mathrm{mrad}$. Standard EXELFS data processing steps [5] were followed to extract partial RDFs: (1) Fourier-ratio single scattering deconvolution with Gatan EL/P software; (2) inverse power-law fit to extract EXELFS oscillations from 310 to $525 \mathrm{eV}$ (range limited by 2 to 4 at.\% oxygen in specimens); (3) oscillation function $\chi(\mathrm{k})$ for $\mathrm{k}$ from 27 to $80 \mathrm{~nm}^{-1}$ generated with the energy threshold held constant at $283 \mathrm{eV}$; and (4) Fast Fourier Transform (FFT) of $\mathrm{k}^{2} \chi(\mathrm{k})$ to yield a partial RDF with a phase shift $\phi=0.038 \mathrm{~nm}$ applied (based on Teo and Lee [6] method), as shown in Fig. 4.

Inspection, analysis, and interpretation of the EFCBED results (Figs. $2 \& 3$ ) lead to the following conclusions [4]. Peaks in $\mathrm{G}(\mathrm{r})$ for $\mathrm{Si} / \mathrm{C}=0.04$ are narrower with a higher peak-to-width ratio than those for $\mathrm{Si} / \mathrm{C}=0.10$. The near-neighbor distances suggest the presence of amorphous hydrogenated $\mathrm{SiC}$ domains. Peaks in $\mathrm{J}(\mathrm{r})$ for $\mathrm{Si} / \mathrm{C}=0.04$ are at 0.16 and $0.28 \mathrm{~nm}$, suggesting the most prominent average bond angle is slightly higher than that for $\mathrm{sp}^{2}$ trigonally bonded $\mathrm{C}\left(122^{\circ}\right.$ versus $\left.120^{\circ}\right)$ and consistent with a slightly distorted graphitic ring structure. The second shell peak in $\mathrm{J}(\mathrm{r})$ for $\mathrm{Si} / \mathrm{C}=$ 
0.10 has a plateau-like shape, indicative of a variety of discrete bond lengths; the $0.19-0.31 \mathrm{~nm}$ pair indicates an average bond angle of $109^{\circ}$, possibly consistent with the presence of C-Si tetrahedral bonding, as in crystalline $\mathrm{SiC}$. The ratio of coordination numbers for the second and first atomic shells obtained from $\mathrm{J}(\mathrm{r})$ is 2.7 for both $\mathrm{Si} / \mathrm{C}=0.04$ and 0.10 , which is intermediate to values for diamond (3.0) and graphite (2.0). The EXELFS results (Fig. 4) lead to the following conclusions [4]. The first nearest-neighbor distance for $\mathrm{Si} / \mathrm{C}=0.04$ is $\sim 0.015 \mathrm{~nm}$ less than that in the other films and is attributed to compressive stress effects. The ratio of second to first shell intensities is higher for $\mathrm{Si} / \mathrm{C}=0.04$ than for the other films, suggesting highly interlinked $\mathrm{C}$ and $\mathrm{Si}$ around $\mathrm{C}$ atoms. Increased deviations from the average bond length are indicated by the wider first nearest-neighbor peak for $\mathrm{Si} / \mathrm{C}=0.0$ and 0.04 . The second nearest-neighbor shells for $\mathrm{Si} / \mathrm{C}=0.0$ and 0.04 extend past the 0.246, 0.285 , and $0.335 \mathrm{~nm}$ positions of crystalline graphite, possibly suggesting any graphitic content is distorted. The second nearest-neighbor shells for $\mathrm{Si} / \mathrm{C}=0.10$ and 0.18 align well with peak positions expected for graphite, suggesting that less-distorted graphite rings are present [7].

1. R.D. Evans, G.L. Doll, P.W. Morrison, Jr., J. Bentley, K.L. More and J.T. Glass, Surf. Coat. Technol. 157 (2002) 197.

2. D.J.H. Cockayne and D.R. McKenzie, Acta Cryst. A44 (1988) 870; D.J.H. Cockayne et al., Microsc. Microanal. Microstruct. 2 (1991) 359; D.J.H. Cockayne et al., Microsc. \& Microanal. 6 (2000) 329

3. R.D. Evans, M.S. Thesis, Case Western Reserve University, 2002.

4. R.D. Evans, J. Bentley, K.L. More, G.L. Doll and J.T. Glass, J. Appl. Phys. 96 (2004) 273.

5. J. Bentley, pp. 155-181 in Transmission Electron Energy-Loss Spectrometry in Materials Science, ed. M.M. Disko, C.C. Ahn, and B. Fultz (TMS, Warrendale, PA 1992).

6. B.K. Teo and P.A. Lee, J. Am. Chem. Soc. 101 (1979) 2815.

7. Research at the ORNL SHaRE User Facility (JB) supported by the Division of Materials Sciences and Engineering, Office of Basic Energy Sciences, and through the ORNL High Temperature Materials Laboratory User Program (KLM and DWC) by the Assistant Secretary for Energy Efficiency and Renewable Energy, Office of Transportation Technologies, U.S. Department of Energy, under contract DE-AC05-000R22725 with UT-Battelle, LLC.

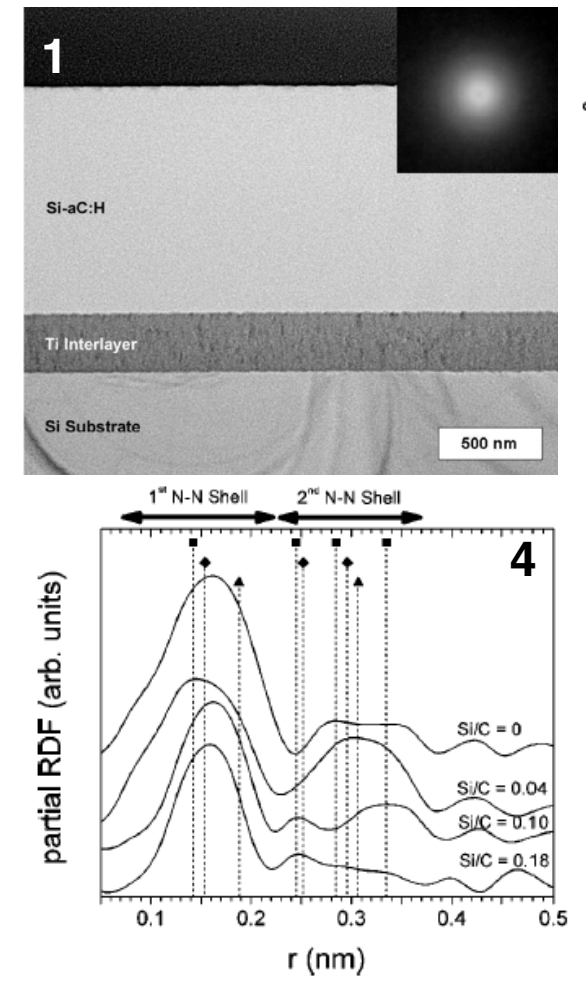



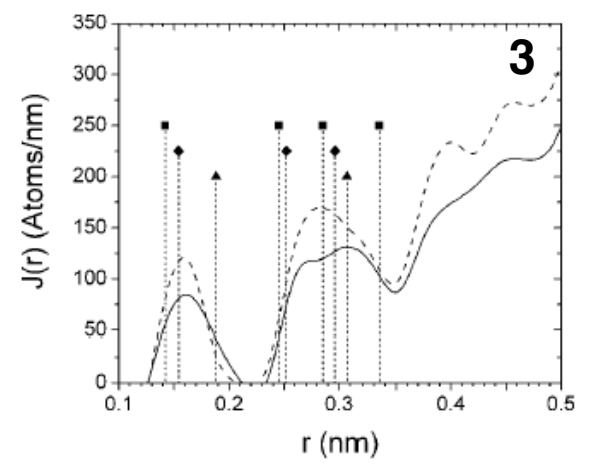

FIG. 1. Cross-sectional TEM image of the film with $\mathrm{Si} / \mathrm{C}=0.10$. SAD pattern for the Si-aC:H layer inset.

FIG. 2. Reduced density function $[\mathrm{G}(\mathrm{r})]$ for the films with $\mathrm{Si} / \mathrm{C}$ $=0.04$ (dashed) and 0.10 (solid).

FIG. 3. Radial distribution functions $[\mathrm{J}(\mathrm{r})]$ for the films with $\mathrm{Si} / \mathrm{C}=0.04$ (dashed) and 0.10 (solid). Vertical line markers represent graphite (square), diamond (diamond), and $\beta$-SiC (triangle) near-neighbor distances.

FIG. 4. Partial RDFs from carbon-K EXELFS. The approximate regions containing first and second nearest-neighbor $(\mathrm{N}-\mathrm{N})$ shells are labeled. Vertical line markers are as in Fig. 3. 